\title{
Akreos Adapt AO Intraocular Lens Opacification: A Case Report
}

\author{
Matteo Forlini ${ }^{a} \quad$ Giancarlo Dell'Aversana Orabona $^{\mathrm{b}}$ \\ Adriana Ionela Bratu ${ }^{c}$ Paolo Rossini ${ }^{c}$ Gian Maria Cavallini ${ }^{a}$ \\ Cesare Forlini ${ }^{\mathrm{C}}$ \\ ${ }^{a}$ Institute of Ophthalmology, University of Modena, Modena, ${ }^{b}$ Department of \\ Ophthalmology, Second University of Naples, Naples, and 'Department of \\ Ophthalmology, Surgical Vitreo-Retinal Unit, 'Santa Maria delle Croci' Hospital, Ravenna, \\ Italy
}

\section{Key Words}

Intraocular lens opacification · Secondary implant · Intraocular lens explantation

\begin{abstract}
A 79-year-old hyperglycemic patient was referred to the 'Santa Maria delle Croci' Hospital, Ravenna, Italy. He presented with visual impairment in the right eye. Four years ago, he had had an uneventful cataract surgery in the right eye. We observed an opacification of the intraocular lens (IOL) causing significant visual disturbance. The IOL was exchanged. Unfortunately, pathologic analysis was not performed. Patient-related factors such as hyperglycemia and hypertension might have been responsible for the opacification. To our knowledge, there is only one previous report of opacification of the Akreos Adapt AO IOL.
\end{abstract}

(C) 2013 S. Karger AG, Basel

\section{Introduction}

Postoperative optic opacification of modern hydrophilic acrylic intraocular lenses (IOL) has been a significant complication leading to IOL explantation since 1999 [1]. The opacification is probably caused by a deposit of calcium and phosphate salts; however, the exact mechanism is unknown [2-5].

The four major designs involved are Hydroview (Bausch and Lomb, Rochester, N.Y., USA), Memorylens (Ciba Vision, Duluth, Ga., USA), SC60B-OUV (Medical Developmental Research, Clearwater, Fla., USA) and Aqua-Sense (Ophthalmic Innovations International,

Matteo Forlini, MD

Institute of Ophthalmology, University of Modena

Via del Pozzo 71

IT-Modena 41100 (Italy)

E-Mail matteoforlini@gmail.com 
Forlini et al.: Akreos Adapt AO Intraocular Lens Opacification: A Case Report

Ontario, Calif., USA) [5, 6]. Early discovery of IOL opacification is important. A wrong diagnosis may in fact prompt surgeons to perform unnecessary surgical procedures like YAG laser capsulotomy or vitrectomy.

This case report discusses late opacification of the Akreos Adapt AO IOL.

\section{Materials and Methods}

In 2008, a 79-year-old Italian man had had a phacoemulsification and hydrophilic acrylic IOL (Akreos Adapt AO, Bausch \& Lomb) implantation in the right eye. The patient had been diagnosed with the pseudoexfoliation syndrome. He had had monocular vision because of an end-stage glaucoma in the left eye. Phacoemulsification had been performed through a clear corneal incision, and a dispersive ophthalmic viscosurgical device (Provisc ${ }^{\circledR}$ ) was used. The patient had had a history of untreated hyperglycemia and hypertension. At that time, the ocular fundus showed no diabetic changes. Preoperatively, the best corrected visual acuity (BCVA) had been 0.4 in the right eye. Two weeks after surgery, the BCVA had improved to 0.9. Postoperative medication included bromfenac $0.9 \mathrm{mg} / \mathrm{ml}$ eyedrops (Yellox) and ofloxacin $0.3 \%$ eyedrops (Exocin), 1 drop 4 times daily for 4 weeks.

In 2011, an Ex-press device had been implanted in the right eye with mitomycin application. Later, he had had a choroidal detachment, for which he had undergone transcleral drainage. In September 2012, the patient complained of decreased visual acuity in the right eye (the BCVA was 0.3). There was significant IOL opacity localized to the anterior surface of the IOL. Complete blood count and the serum calcium level were within normal ranges. The IOL was explanted together with the capsular bag, and an iris-claw lens (Artisan Aphakia OPHTEC) was implanted.

\section{Results}

The Akreos Adapt AO IOL showed widespread deposits that seem to be inside the optic (fig. 1, fig. 2). Scratching of the lens did not remove the deposits. Chemical and histopathological analysis was not carried out for the unavailability of the lens; however, the deposits were similar to another case described by Lee et al. [7] in 2010. After the operation, our patient had a BCVA of 0.6 in the right eye and no other complications.

\section{Conclusion}

IOL opacification is a rare but possible event. The exact reason for the opacification is unknown. This alteration is most common in patients with diabetes or hypertension [8]. A case of an Akreos Adapt AO IOL opacification was described by Lee et al. [7] in a patient with diabetes and hypertension. Metabolic imbalance, altered fluid dynamics of the aqueous, or a breakdown of the blood-aqueous barrier in diabetic patients, combined with other factors, may be responsible for the opacification [8,9]. In the present case, the deposits probably consisted of calcium-phosphorus aggregates as described in other diabetic or hyperglycemic patients. 
Forlini et al.: Akreos Adapt AO Intraocular Lens Opacification: A Case Report

\section{Disclosure Statement}

The authors did not receive any financial support from any public or private sources.

\section{References}

1 Werner L: Causes of intraocular lens opacification or discoloration. J Cataract Refract Surg 2007;33:713726.

2 Werner L, Apple DJ, Kaskaloglu M, Pandey SK: Dense opacification of the optical component of a hydrophilic acrylic intraocular lens: a clinicopathological analysis of 9 explanted lenses. J Cataract Refract Surg 2001;27:1485-1492.

-3 Neuhann IM, Werner L, Izak AM, et al: Late postoperative opacification of a hydrophilic acrylic (hydrogel) intraocular lens: a clinicopathological analysis of 106 explants. Ophthalmology 2004;111:2094-2101.

-4 Guan X, Tang R, Nancollas GH: The potential calcification of octacalcium phosphate on intraocular lens surfaces. J Biomed Mater Res A 2004;71:488-496.

5 Werner L, Hunter B, Stevens S, Chew JJL, Mamalis N: Role of silicon contamination on calcification of hydrophilic acrylic intraocular lenses. Am J Ophthalmol 2006;141:35-43.

-6 Mak ST, Wong AC-M, Tsui WM-S, Tse RK-K: Calcification of a hydrophilic acrylic intraocular lens: clinicopathological report. J Cataract Refract Surg 2008;34:2166-2169.

$>7$ Lee CE, Kim YC, Chang SD: Opacification of the optic of an Akreos Adapt intraocular lens. Korean J Ophthalmol 2010;24:371-373.

-8 Macky TA, Werner L, Soliman MM, Pandey SK, Izak AM, Apple DJ: Opacification of two hydrophilic acrylic intraocular lenses 3 months after implantation. Ophthalmic Surg Lasers Imaging 2003;34:197-202.

-9 Groh MJ, Schlotzer-Schrehardt U, Rummelt C, et al: Postoperative opacification of 12 hydrogel foldable lenses (Hydroview ${ }^{\circledR}$ ). Klin Monbl Augenheilkd 2001;218:645-648. 
Case Reports in

Ophthalmology

\begin{tabular}{l|l}
\hline Case Rep Ophthalmol 2013;4:151-154 \\
\hline DOI: $10.1159 / 000355414$ & $\begin{array}{l}\text { @ 2013 S. Karger AG, Basel } \\
\text { www.karger.com/cop }\end{array}$ \\
\hline
\end{tabular}

Forlini et al.: Akreos Adapt AO Intraocular Lens Opacification: A Case Report

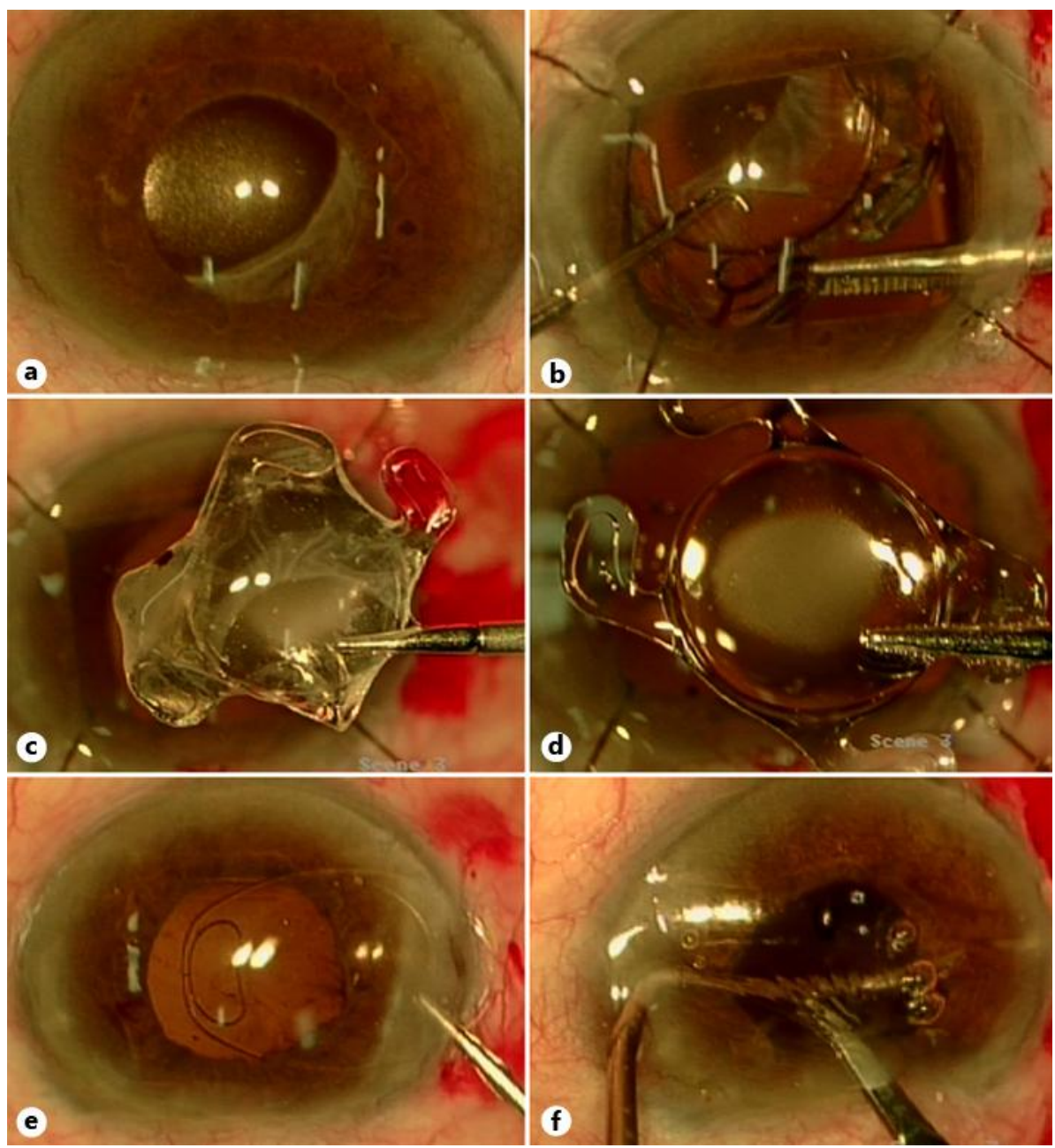

Fig. 1. Surgical exchange of an opacified Akreos Adapt AO IOL. a-d Opacified IOL explantation together with the capsular bag. e, $f$ Iris-claw lens implantation on the posterior surface of the iris.
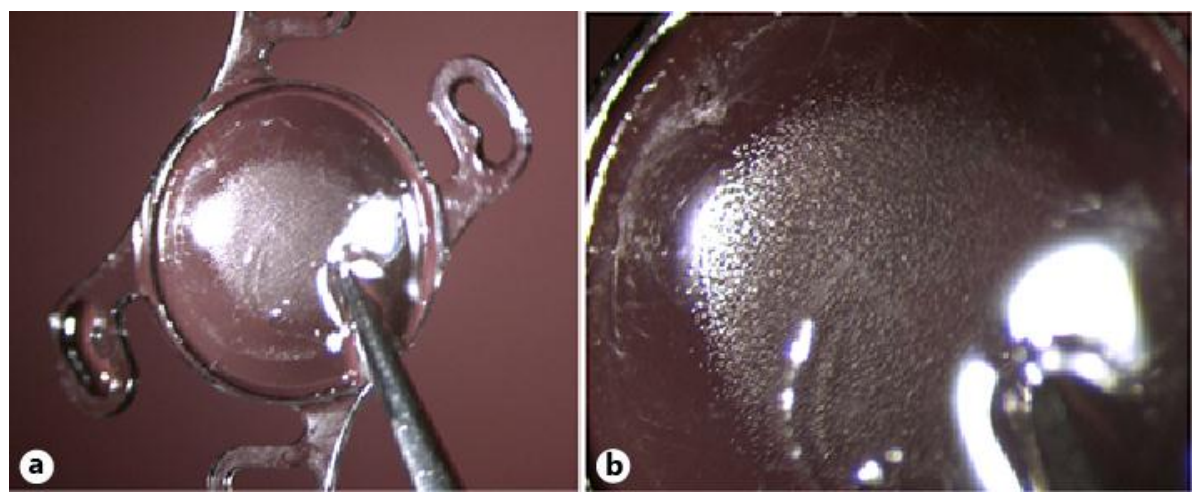

Fig. 2. After the explantation, the Akreos Adapt AO IOL showed diffuse deposits that seem to be inside the optic. 